\title{
External Magnetic Field Effect on Bifacial Silicon Solar Cell's Electrical Parameters
}

\author{
Issa Zerbo, Martial Zoungrana, Idrissa Sourabié, Adama Ouedraogo, Bernard Zouma, \\ Dieudonné Joseph Bathiebo \\ Department of Physics, Laboratory of Thermal and Renewable Energies, Unit of Training and Research in Pure \\ and Applied Sciences, University of Ouagadougou Joseph Ki-Zerbo, Ouagadougou, Burkina Faso \\ Email: izerbo@univ-ouaga.bf
}

Received 13 February 2016; accepted 13 March 2016; published 16 March 2016

Copyright (C) 2016 by authors and Scientific Research Publishing Inc.

This work is licensed under the Creative Commons Attribution International License (CC BY). http://creativecommons.org/licenses/by/4.0/

(c) (i) 0pen Access

\begin{abstract}
The aim of this work is to present a theoretical study of external magnetic field effect on a bifacial silicon solar cell's electrical parameters (peak power, fill factor and load resistance) using the J-V and $\mathrm{P}-\mathrm{V}$ characteristics. After the resolution of the magneto transport equation and continuity equation of excess minority carriers in the base of the bifacial silicon solar cell under multispectral illumination, the photo-current density and the photovoltage are determined and the J-V and P-V curves are plotted. Using simultaneously the J-V and P-V curves, we determine, according to magnetic field intensity, the peak photocurrent density, the peak photovoltage, the peak electric power, the fill factor and the load resistance at the peak power point. The numerical data show that the solar cell's peak power decreases with magnetic field intensity while the fill factor and the load resistance increase.
\end{abstract}

\section{Keywords}

Bifacial Silicon Solar Cell, Fill Factor, Load Resistance, Magnetic Field, Peak Power

\section{Introduction}

The efficiency of a solar cell depends on its electrical parameters such as series and shunt resistances, peak power and fill factor. For the determination of the series and shunt resistances many authors [1]-[3] used the photocurrent density-photovoltage (J-V) characteristic of a solar cell while other authors [4] used simultaneously the photocurrent density-photovoltage $(\mathrm{J}-\mathrm{V})$ and the electric power-photovoltage $(\mathrm{P}-\mathrm{V})$ characteristics for the determination of electrical parameters such as peak power, fill factor and load resistance. In a previous work we have studied the influence of magnetic field intensity on a bifacial silicon solar cell's electric power and conver- 
sion efficiency using the electric power curves versus junction dynamic velocity [5].

In this work, we study the influence of magnetic field intensity on a bifacial silicon solar cell's electrical parameters (peak power, fill factor and load resistance). Using simultaneously the J-V and P-V curves, we determine the peak power, the fill factor and the load resistance at the peak power point according to magnetic field intensity. Then, we relate the resistance at the peak power point $\left(\mathrm{R}_{\mathrm{MPP}}\right)$ to the junction dynamic velocity at the maxi mum power point $\left(\mathrm{Sf}_{\mathrm{MPP}}\right)$ calculated in the previous article [5].

\section{Theory}

\subsection{Excess Minority Carriers' Density}

This study is focused on the base region of a polycrystalline back surface field bifacial silicon solar cell (Figure 1) in the quasi-neutral base assumption [5] [6].

When the bifacial silicon solar cell is illuminated simultaneously on both sides, the solution of excess minority carriers' continuity equation [7] is:

$$
\delta(x, B)=A_{1} \cdot \operatorname{ch}\left(\frac{x}{L_{n}^{*}}\right)+A_{2} \cdot \operatorname{sh}\left(\frac{x}{L_{n}^{*}}\right)+\sum_{i=1}^{3} K_{i} \cdot\left[\mathrm{e}^{-b_{i} \cdot x}+\mathrm{e}^{-b_{i}(H-x)}\right]
$$

with $K_{i}=-a_{i} \cdot\left[D_{n}^{*} \cdot\left(b_{i}^{2}-\frac{1}{L_{n}^{* 2}}\right)\right]^{-1}$.

In Equation (1), $L_{n}^{*}$ and $D_{n}^{*}$ are respectively electrons' diffusion length and diffusion coefficient in the presence of a magnetic field, coefficients $a_{i}$ and $b_{i}$ are tabulated values obtained from modelling of the generation rate considered for over all the solar radiation spectrum under Air Mass 1, 5 standard conditions [8] and $\mathrm{H}$ is the base thickness.

Constants $A_{1}$ and $A_{2}$ are determined solving the boundary conditions [5] [7]. Thus, the excess minority carriers' (electrons) density will be completely determined.

\subsection{Photocurrent Density}

Since the excess minority carriers' density is known, from Fick's law applied at the solar cell junction, we can derive the photocurrent density expression as:

$$
\left.\operatorname{Jph}(S f, B)=q \cdot D_{n}^{*} \cdot \frac{\partial \delta(x, S f, B)}{\partial x}\right)_{x=0} .
$$

\subsection{Junction Photovoltage}

Knowing the excess minority carriers' density, the photovoltage across the solar cell junction is also expressed

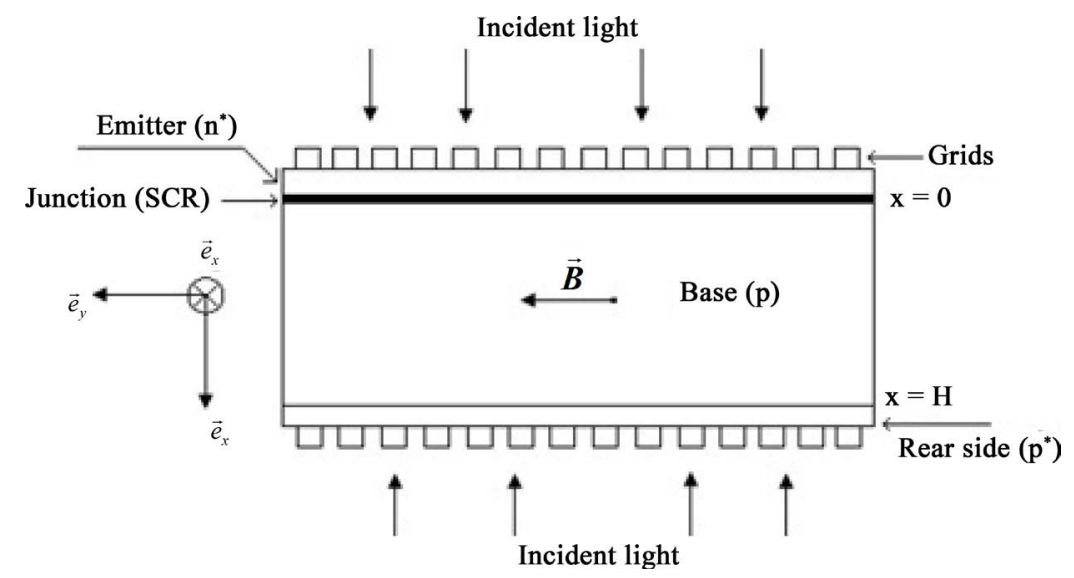

Figure 1. Bifacial silicon solar cell illuminated by multispectral light and under magnetic field influence. 
using Boltzmann’s relation:

$$
\operatorname{Vph}(S f, B)=V_{T} \cdot \ln \left(N_{B} \frac{\delta(x=0, S f, B)}{n_{i}^{2}}+1\right)
$$

$V_{T}$ is the thermal voltage, $n_{i}$ is the intrinsic carriers' density at thermodynamic equilibrium and $N_{B}$ is the base doping density.

\subsection{Photocurrent Density-Photovoltage Characteristics (Jph-Vph)}

The photocurrent density and the photo-voltage depend on junction dynamic velocity Sf. While taking the junction dynamic velocity as parameter, we plot in Figure 2 the solar cell Jph-Vph characteristic curves for different values of magnetic field intensity.

The shapes of the different curves in Figure 2 show that the short circuit photocurrent density is a decreasing function of magnetic field while the open circuit photovoltage is an increasing function of the same magnetic field. We note that the short circuit photocurrent density decreases strongly while the open circuit photovoltage increases slightly.

Each curve is characterized by three remarkable points: the short circuit photocurrent density $J_{s c}$, the open circuit photovoltage $V_{o c}$ and a point named "knee" or peak power point [4] which has $J_{m}$ (or $J_{p}$ ) and $V_{m}$ (or $V_{p}$ ) as coordinates [1] The peak power $\left(P_{p}=J_{p} \times V_{p}\right)$ is the maximum electric power $\left(P_{m}=J_{m} \times V_{m}\right)$ that a solar cell can delivered to an external circuit; so the peak power point is the operating point that permits to obtain the maximum electric power from a solar cell [4]. We note a displacement of the peak power point, towards large values of photovoltage and low values of photocurrent density, when the magnetic field intensity increases and that situation corresponds to a displacement of the solar cell's operating point and so an increase of the load resistance at the peak power point.

\subsection{Electric Power-Photovoltage Characteristics (P-Vph)}

The expression of electric power delivered by the base of the bifacial solar cell to an external circuit is:

$$
P(S f, B)=V p h(S f, B) \cdot J p h(S f, B)_{T}
$$

with $\operatorname{Jph}(S f, B)_{T}=q \cdot S f_{j} \cdot \delta(x=0, S f, B)$ which is the photocurrent density that crosses the external load resistance.

The electric power delivered by the bifacial silicon solar cell to an external circuit depends also on the junction dynamic velocity Sf. While taking the junction dynamic velocity as parameter, we plot in Figure 3 the solar cell P-Vph characteristic curves for different values of magnetic field intensity.

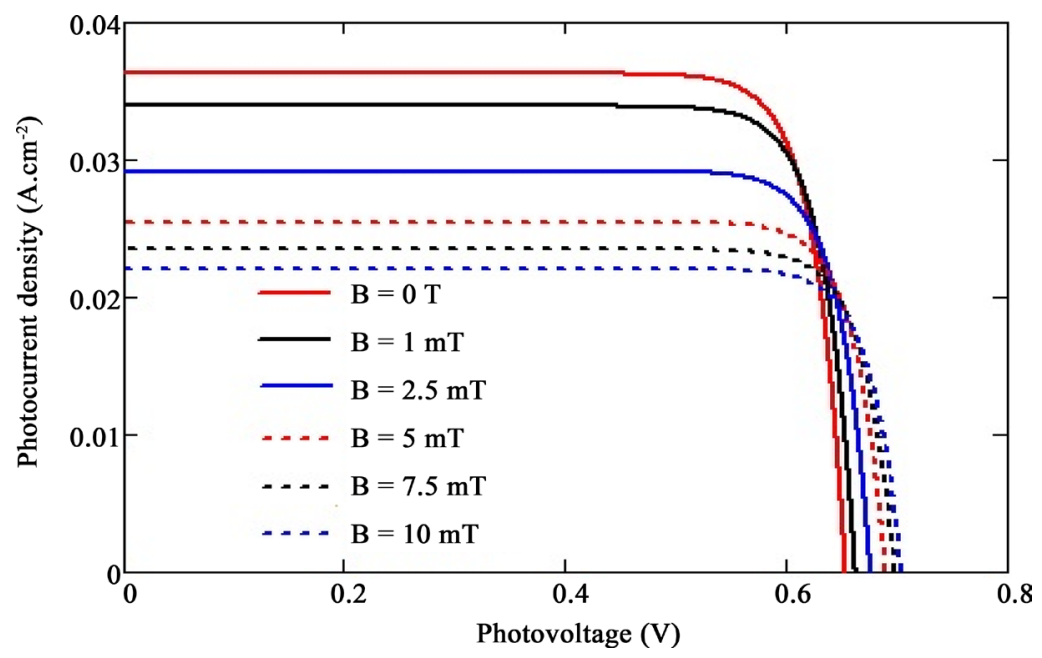

Figure 2. Photocurrent density-photovoltage curves for various magnetic field intensity $\left(L=0.02 \mathrm{~cm} ; H=0.03 \mathrm{~cm} ; D=26 \mathrm{~cm}^{2} / \mathrm{s} ; \mu_{n}=1000 \mathrm{~cm}^{2} / \mathrm{V} . \mathrm{s}\right)$. 
The curves in Figure 3 show that the peak power decreases with magnetic field increase and that corresponds to a displacement of the bifacial solar cell's operating point towards large values of photovoltage. This means that the increase of magnetic field leads to an increase of the load resistance at the peak power point.

\section{Results and Discussion}

\subsection{Method of Electrical Parameters Determination}

For that, we plot in the same axes system (Figure 4), Jph-Vph and P-Vph characteristics for a given magnetic field intensity.

Using the two characteristics, we determine the values of peak power $P_{p}$, peak photovoltage $V_{p}$, peak photocurrent density $J_{p}$, short circuit photocurrent density $J_{s c}$ and open circuit photovoltage $V_{o c}$ according to magnetic field intensity.

Then we calculated the solar cell fill factor $(F F)$ using the formula below:

$$
F F=\frac{V_{p} \cdot J_{p}}{V_{o c} \cdot J_{s c}} .
$$

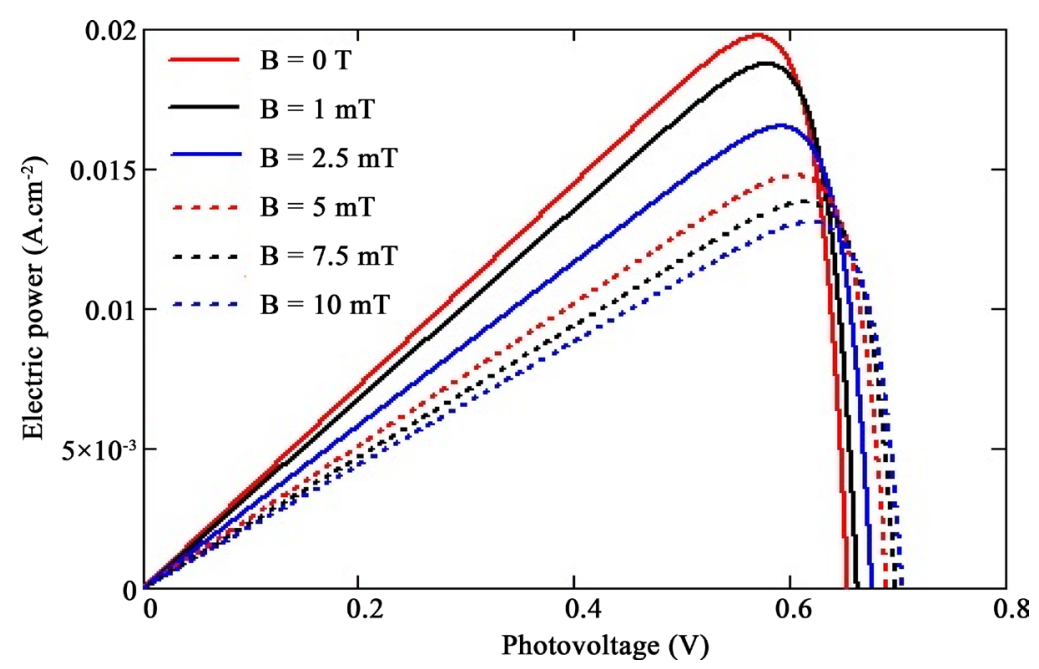

Figure 3. Electric power-photovoltage curves for various magnetic field intensity ( $L=0.02$ $\left.\mathrm{cm} ; H=0.03 \mathrm{~cm} ; D=26 \mathrm{~cm}^{2} / \mathrm{s} ; \mu_{n}=1000 \mathrm{~cm}^{2} / \mathrm{V} . \mathrm{s}\right)$.

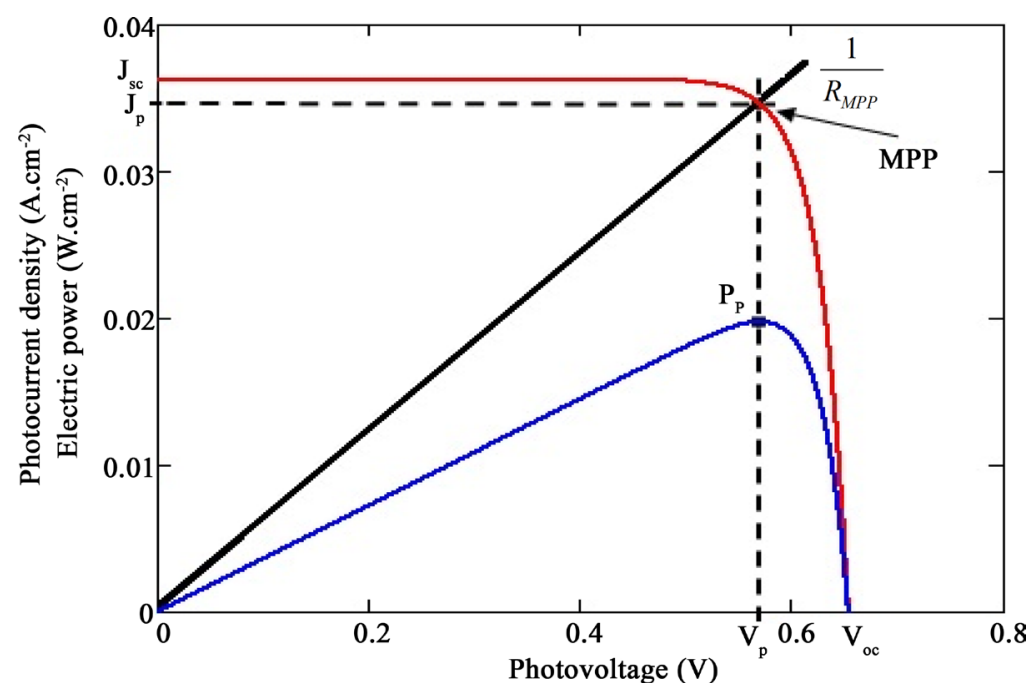

Figure 4. Electrical parameters determination using Jph-Vph and P-Vph characteristics. 
Knowing the peak photovoltage $V_{p}$, and the peak photocurrent density $J_{p}$, we calculated the load resistance at ${ }^{2}$ the peak power point (Maximum Power Point) using Ohm’s law [4]:

$$
R_{M P P}=\frac{V_{p}}{J_{p}} .
$$

\subsection{Electrical Parameters Values}

The characteristic values of the bifacial solar cell under magnetic field are given in Table 1.

These results show that the peak photocurrent density and the short circuit photocurrent density decrease with magnetic field intensity while the peak photovoltage and the open circuit photovoltage increase with the same magnetic field intensity. These results have been observed on the Jph-Vph characteristics. The peak power decreases with the magnetic field intensity while the fill factor and the load resistance at the maximum power point or peak power point increase. The decrease of peak power with magnetic field increase corresponds to a displacement of the bifacial solar cell's operating point towards large values of photovoltage, resulting in an increase of charge resistance at the peak power point.

In Table 2, we give the values of maximum electric power delivered by the solar cell to an external circuit and the values of junction dynamic velocity at the maximum power point [5]. We also give the values of the load resistance at the peak power point, determined in this work.

We note that the maximum electric power determined in the previous work [5] is in the same order of size that the peak power determined in this work. One notes also that the junction dynamic velocity at the peak power point and the load resistance at the peak power point evolve in reverse senses. Indeed, when the junction dynamic velocity decreases one evolves towards the open circuit and the load resistance increases. On the other hand, when the junction dynamic velocity increases, one evolves towards the short circuit and the load resistance decreases.

\section{Conclusions}

In this work, we have presented a theoretical study of magnetic field influence on the electrical parameters of a bifacial silicon solar cell. Taking as parameter the junction dynamic velocity, we plot the solar cell $J p h$-Vph and $P$-Vph characteristics. The peak power, the peak photovoltage, the peak photocurrent density, the short circuit photocurrent density and the open circuit photovoltage are determined by means of the $J p h-V p h$ and $P$-Vph characteristics according to magnetic field intensity. Then we calculated the solar cell fill factor (FF) and the load resistance at the peak power point using Ohm's law.

The numerical data are evidence of an increase in the fill factor and the load resistance at the peak power

Table 1. Bifacial silicon solar cell’s electrical parameters for different values of magnetic field intensity.

\begin{tabular}{ccccccc}
\hline$B(\mathrm{mT})$ & 0 & 1 & 2.5 & 5 & 7.5 & 10 \\
$P_{p}\left(\mathrm{~mW} / \mathrm{cm}^{2}\right)$ & 19.759 & 18.757 & 16.526 & 14.776 & 13.810 & 13.104 \\
$V_{p}(\mathrm{mV})$ & 571.150 & 578.250 & 592.120 & 604.700 & 612.110 & 619.460 \\
$J_{p}\left(\mathrm{~mA} / \mathrm{cm}^{2}\right)$ & 34.591 & 32.437 & 27.952 & 24.435 & 22.561 & 21.167 \\
$V_{o c}(\mathrm{mV})$ & 653.890 & 662.690 & 676.430 & 690.000 & 698.270 & 704.400 \\
$J_{\text {sc }}\left(\mathrm{mA} / \mathrm{cm}^{2}\right)$ & 36.272 & 33.909 & 29.183 & 25.507 & 23.512 & 22.095 \\
$F F$ & 0.833 & 0.835 & 0.838 & 0.840 & 0.841 & 0.842 \\
$R_{M P P}\left(\Omega . \mathrm{cm}^{2}\right)$ & 16.512 & 17.827 & 21.183 & 24.747 & 27.177 & 29.265 \\
\hline
\end{tabular}

Table 2. Bifacial silicon solar cell’s recombination and electrical parameters for various magnetic field intensity.

\begin{tabular}{ccccccc}
\hline$B(\mathrm{mT})$ & 0 & 1 & 2.5 & 5 & 7.5 & 10 \\
$P_{\max }\left(\mathrm{mW} / \mathrm{cm}^{2}\right)$ & 19.759 & 18.757 & 16.526 & 14.775 & 13.810 & 3.104 \\
$S f_{M P P}(\mathrm{~cm} / \mathrm{s})$ & $2.928 \times 10^{4}$ & $1.942 \times 10^{4}$ & $1.027 \times 10^{4}$ & $5.727 \times 10^{3}$ & $3.862 \times 10^{3}$ & $2.922 \times 10^{3}$ \\
$R_{M P P}\left(\Omega . \mathrm{cm}^{2}\right)$ & 16.512 & 17.827 & 21.183 & 24.747 & 27.177 \\
\hline
\end{tabular}


point with the increase of the magnetic field intensity but a decrease in the peak power. We interpreted the variation in the load resistance at the peak power point as a variation in the solar cell's operating point. The load resistance at the peak power point has been related to the junction dynamic velocity at the maximum power point determined in a previous work. We noted that the junction dynamic velocity and the load resistance at the peak power point evolve in reverse senses. This last analysis permits to conclude that the junction dynamic velocity defines effectively the solar cell operating point.

\section{Acknowledgements}

The authors thank International Science Program (ISP) for supporting their research group (energy and environment) and allowing them to conduct this work.

\section{References}

[1] Mbodji, S., Ly, I., Diallo, H.L., Dione, M.M., Diasse, O. and Sissoko, G. (2012) Modeling Study of N ${ }^{+} / \mathrm{P}$ Solar Cell Resistances from Single I-V Characteristic Curve Considering the Junction Recombination Velocity (Sf). Research Journal of Applied Sciences, Engineering and Technology, 4, 1-7.

[2] Ould El Moujtaba, M.A., Ndiaye, M., Diao, A., Thiame, M., Barro, I.F. and Sissoko, G. (2012) Theoretical Study of the Influence of Irradiation on a Silicon Solar Cell under Multispectral Illumination. Research Journal of Applied Sciences, Engineering and Technology, 4, 5068-5073.

[3] Sane, M. and Barro, F.I. (2015) Effect of Both Magnetic Field and Doping Density on Series and Shunt Resistances under Frequency Modulation. Indian Journal of Pure and Applied Physics, 53, 590-595.

[4] Sow, O., Zerbo, I., Mbodji, S., Ngom, M.I., Diouf, M.S. and Sissoko, G. (2012) Silicon Solar Cell under Electromagnetic Waves in Steady State: Electrical Parameters Determination Using the I-V and P-V Characteristics. International Journal of Science Environment and Technology, 1, 230-246.

[5] Zerbo, I., Zoungrana, M., Sourabie, I., Ouedraogo, A., Zouma, B. and Bathiebo, D.J. (2015) External Magnetic Field Effect on Bifacial Silicon Solar Cell's Electric Power and Conversion Efficiency. Turkish Journal of Physics, 39, 288294. http://dx.doi.org/10.3906/fiz-1505-10

[6] Misiakos, K., Wang, C.H., Naugroschel, A. and Lindholm, F.A. (1990) Simultaneous Extraction of Minority Carrier Parametres in Crystalline Semiconductors by Lateral Photocurrent. Journal of Applied Physics, 67, 321-333. http://dx.doi.org/10.1063/1.345256

[7] Madougou, S., Made, F., Boukary, M.S. and Sissoko, G. (2007) I-V Characteristics for Bifacial Silicon Solar Cell Studied under a Magnetic Field. Advanced Materials Research, 18-19, 303-312. http://dx.doi.org/10.4028/www.scientific.net/AMR.18-19.303

[8] Mohammad, S.N. (1987) An Alternative Method for the Performance Analysis of Silicon Solar Cells. Journal of Applied Physics, 61, 767-772. http://dx.doi.org/10.1063/1.338230 